\title{
Parempaan, eriarvoiseen Suomeen
}

Pursiainen, Heikki (2017). Paska Suomi. Tammi. 276 sivua.

AJATUSPAJA LIBERAN tutkimusjohtajana vuosina 2015-17 toimineen Heikki Pursiaisen ensimmäinen kirja ottaa käsittelyyn ison joukon ajankohtaisia yhteiskunnallisesti merkittäviä teemoja. Suomessakin riittää epäkohtia, jotka on syytä nostaa ruodittaviksi julkisuuteen. Pursiainen koettaa ravistella ajasta jälkeen jääneitä, luutuneina ajattelutottumuksia siitä, miten talous ja työmarkkinat saataisiin toimimaan tehokkaammin.

Kirjan keskeinen viesti on valtion ja muunkin julkisen vallan roolin kyseenalaistaminen: julkisen (valtio) ja yksityisen (yritykset) toiminnan tehtävät ja vastuut pitäisi järjestää uudelleen. Valtion tehtäviä pitäisi reilusti karsia ja siirtää palveluja yksityisten yritysten tuotettavaksi. Se tervehdyttäisi taloutta ja vähentäisi kansalaisten holhoamista.

Tämä vain ei onnistu, koska poliittinen järjestelmä on niin rappeutunut. Puolueilta on muu paitsi oman edun turvaamisen ajatus hukassa. Puolueet ajavat vääriä asioita. Kaikki rakastavat veronkeruuta ja valtiota.

\section{SOMESTA TUTTU}

Kun kirja alkaa lauseella "Suomi on paska maa satavuotispäivänään", lukija aloittaa lukurupeaman epäuskoisena. Millainen on kirjoittajan havainnointikyky? Entä suhteellisuudentaju? Tai ehkäpä kirjoittaja on koonnut yksiin kansiin käymi- ään somekeskusteluja, joissa vääristely, liioittelu ja solvaaminen tuntuvat olevan yhä useammalle keskustelijalle luontaista:

"Poliittinen järjestelmä on surullisessa tilassa. Silti kaikki toivovat ja luottavat valtion hoitavan kaiken ja pelastavan kaiken. Ei ole mitään ongelmaa, jota ei voitaisi hoitaa viskaamalla tukku verorahoja sen suuntaan. [--] Valtio työllistää työttömät. Valtio hoitaa, maksaa, ottaa vastuun ja tekee päätökset meidän puolestamme. Kenenkään ei tarvitse itse tehdä mitään.” (s. 10-11.)

Pursiaisen tyylilajiin sopeutuminen lienee monelle vaikeaa. Ei ole aivan helppo ymmärtää, millaisiin havaintoihin hänen väitteensä perustuvat. Itse en ole nähnyt sellaista Suomea, missä kenenkään ei tarvitse tehdä mitään. Kyllä tällä valtaosa väestöstä joutuu käymään ahkerasti töissä.

En käy arvailemaan, millaisia tilastoja Pursiainen on kirjaa varten tutkinut, mutta esimerkiksi työ- ja elinkeinoministeriön (TEM) tilastoista ei voi päätellä valtion työllistäneen työttömät. Niiden mukaan mukaan työttömiä työnhakijoita oli noin 300000 vuonna 2017.

\section{PUOLUEILTA TEHTÄVÄT}

HUKASSA

Kirjoittaja käy puolueet läpi yksitellen ja osoittaa tyytymättömyyden aiheensa niissä kussakin.

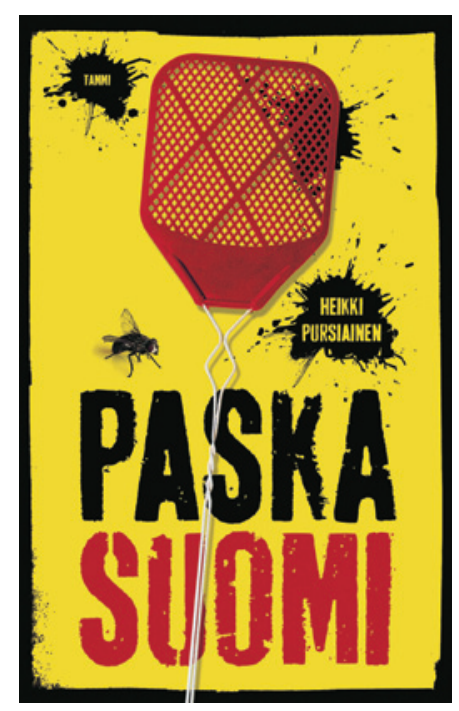

Vasemmisto ei ole enää vasemmistolainen, eivätkä oikeistopuolueet uskalla edustaa oikeistolaista politiikkaa. Keskustapuolue on Suomea tuhoavan voiman kultti. Vihreät on niin mitätön, ettei siitä ole mitään sanottavaa.

Menneisyyteen haikailevalla vasemmistolla ei ole positiivista tulevaisuudenvisiota. Se vastustaa kaikkea muutosta. Vasemmisto on unohtanut vähäosaiset ja ajaa politiikkaa, joka estää työttömiä työllistymästä ja köyhiä rikastumasta.

Suomessa ei ole Pursiaisen mielestä yhtään oikeistopuoluetta, jota "edes vähän sivistynyt ihminen voisi kuvitella kannattavansa" (s. 38) Kokoomuksestakaan ei ole markkinatalouspuolueeksi, joka uskaltaisi jättää talouden markkinoiden vastuulle. Pursiaisen mukaan "kunnon oikeisto olisi markkinataloushenkinen. Se veisi valtion pois liiketoiminnasta, 
poistaisi tukiaiset, rakastaisi kilpailua ja vihaisi erioikeuksia, kartelleja ja monopoleja. [--] Kunnon oikeisto luottaisi markkinatalouteen eikä olisi koko ajan näpertämässä ja säätämässä sitä. Kaikki ne asiat, joita ei tarvitse säätää, jätettäisiin säätämättä. Kaikki ne asiat, joita valtion ei ole pakko hoitaa, jätettäisiin hoitamatta."

Pursiainen surkuttelee, ettei mikään oikeistopuolue kannata "kovaa markkinataloutta". Sen sijaan puolueet vaalivat yhdessä "pehmeää markkinataloutta". Pursiaisen näkemyksen mukaan "kova markkinatalous nimittäin on sellainen, joka pakottaa yritykset kilpailemaan ihmisten eduksi." (s. 69.) Luultavasti oikeistopuolueissa toimivat ovat sen verran enemmän elämää nähneitä, että ovat havainneet kovan markkinatalouden riskit muualla maailmassa.

Pursiainen haluaisi vasemmiston pois talouspolitiikasta. Sen olisi parasta keskittyä ajamaan köyhien etua eikä puuttua talouteen. On vaikea hahmottaa, miksi puolueet ottaisivat Pursiaisen toiveet todesta. Miksi Kokoomus ryhtyisi ajamaan vain kovaa markkinataloutta, ja miksi vasemmistopuolueet keskittyisivät köyhäinhoitoon? Ajatus on yksi kirjan kummallisuuksista. Se on empiriasta irrallista nojatuolifilosofointia.

\section{ERIARVOISUUDEN PUOLUSTUS}

Paska Suomi hyökkää eriarvoisuudesta käytävää keskustelua vastaan. Pursiaisen mukaan eriarvoisuus ei ole pahasta. Tuloeroina konkretisoituvaa eriarvoisuutta tarvitaan. Tuloerot kannustavat ihmisiä yrittämään. Jos yksilöiden yritteliään toiminnan seurauksena yksi omistaa enemmän kuin joku toinen, se ei ole ongelma. Se on juhlan aihe, Pursiainen ajattelee. Köyhienkin pitäisi juhlia sitä, koska heidän osansa ei rikkaiden rikastumisen seurauksena huonone.

Pursiainen ei puuttuisi eriarvoisuuteen sinänsä. Sen sijaan köyhiä hänkään ei jättäisi auttamatta. Eriarvoisuudesta puhuminen pitäisi lopettaa ja puhua sen sijaan köyhien auttamisesta. Jostain syystä hän ei suostu ymmärtämään, että sosiaalista ja taloudellista eriarvoisuutta tarkkaillaan jatkuvasti juuri siksi, että osoitetaan, miten köyhiä tulonjaon matalimmassa päässä olevat ovat, ja miten esimerkiksi kasvavan talouden hedelmät jakautuvat. "Eriarvoisuushaukat" vahtivat tulonjakotilastoja juuri siksi, että voitaisiin vaikuttaa jo ennen kuin pienituloiset vajoavat köyhyyteen Pursiaisen autettaviksi.

Kirjoittaja kieltäytyy myös myöntämästä sitä, että eriarvoi- suudella ja epätasaisella tulonjaolla voisi olla haitallisia vaikutuksia. Väitteet siitä, että kansalaiset olisivat tyytymättömiä kovin epätasaisen tulonjaon takia, on hänestä höpöhöpöä. Tai jos ihmiset ovatkin tyytymättömiä, se on heidän henkilökohtainen ongelmansa, ei yhteiskunnallinen ongelma. Valtion ei pitäisi puuttua siihen.

Kirjan puolustama kuva yhteiskunnasta on individualistinen. Jokainen on oman onnensa seppä ja vastuussa markkina-arvostaan ja esimerkiksi työllisyydestään. "Pienet tulot ovat oma vapaaehtoinen valinta", Pursiainen kirjoittaa (s. 21). Ekonomistin väitettä voi hyvällä syyllä sanoa teoreettiseksi. Siinä annetaan "vapaaehtoiselle valinnalle" sisältö, joka on vailla yhteyttä empiiriseen todellisuuteen.

Pienituloisen valitus siitä, että palkalla pitäisi tulla toimeen, on kirjoittajan mukaan "älytön". Palkan suuruus määräytyy puolueettomasti markkinoilla, eikä valitusoikeutta ole. Eikä pidäkään olla, koska markkinoihin ei pidä puuttua. Palkat eivät ole poliittisen päätöksenteon asia.

Pursiainen kavahtaa myös vaatimuksia, että päätöksenteossa pitäisi koettaa ennalta arvioida vaikutuksia esimerkiksi sukupuolten tasa-arvoon. Jos eriarvoisuus lisääntyy, sitten se lisääntyy. 
TASA-ARVOISTAVA JA ERIARVOISTA KOULUTUS

Suomessa on totuttu ajattelemaan koulutusta tasa-arvoistavana instituutiona. Pursiaisen mielestä tämä ajatus on virheellinen. Perusasteella tasa-arvo on otettava huomioon ja lähtökohtien erilaisuutta on sallittua edistää kompensoivilla toimenpiteillä. Mutta perusasteen jälkeen, erityisesti korkeakoulutuksessa, tasa-arvon tavoittelu pitäisi unohtaa. Korkeakoulutuksen tavoitteena on Pursiaisen mukaan nimenomaan eriarvoisuuden lisääminen.

Totta on, että koulutusjärjestelmä legitimoi eriarvoisuutta. Mutta koulutuksen tuottaman eriarvoisuuden ihannointi Pursiaisen tyylin on sellaista äriajattelua, jossa on pakko unohtaa koulutusinstituution historiallinen ja yhteiskunnallinen konteksti. Koulutusjärjestelmä ei ole puolueeton markkinamekanismi.

Pursiainen hyväksyy koulujen ja oppilaiden eriytymisen, eikä näe sitä ongelmana. "Jos lahjakkaimmat oppivat parhaiten ryhmissä, joissa kaikki ovat lahjakkaita, eriyttäminen on hyvä asia”, hän päättelee. Todellisuudessa kyseessä on tietynlainen nollasummapeli. Kun hyvät oppilaat keskitetään omiin luokkiin tai omiin kouluihin, toisaalle syntyy huonosti menestyvien oppilaiden ryhmiä. Hyvät oppilaat varmaankin hyötyvät tällaisesta eriyttämisestä, mutta huonommat kärsivät. Tähän tulokseen on päädytty esimerkiksi PISAaineistoja analysoimalla. Kirjoittaja nähtävästi priorisoi eriyttämistä, joka koituu nimenomaan lahjakkaimpien eduksi, vaikka se samalla huonontaa huonommin menestyvien asemaa.
Pursiainen ei hyväksy sitä, että tulojen ja koulutuksen periytyvyyttä ylipäätään pidetään ongelmana. Hänen ajatuksensa menee näin: "Tulojen ja koulutuksen periytyminen on kuitenkin myös hyvä asia. Kaikki me toivomme pystyvämme jättämään lapsillemme perintöä. Jos olemme korkeasti koulutettuja, suurin toiveemme on, että myös lapsistamme tulisi korkeasti koulutettuja. [--] Tämä hyvien asioiden periytyminen omille lapsille on monien ihmisten keskeisimpiä päämääriä elämässä. Ja hyvä yhteiskunta on sellainen, missä sen jäsenillä on mahdollisuus toteuttaa omia päämääriään mahdollisimman hyvin. Varallisuuden ja koulutuksen periytyminen ovat siis hyviä, eivät huonoja asioita." (s. 235-236.)

Opiskelupaikat ovat nollasummapeliä. Yhden saama paikka on pois toiselta. Kun esimerkiksi pääsy yliopistoihin on rajattu tietyksi määräksi aloituspaikkoja, on Pursiaisen mukaan nähtävästi hyvä, että niihin valitaan opiskelijat niistä perheistä, joissa vanhemmillakin on yliopistokoulutus. Tämä olisi oikein siksi, että akateemiset vanhemmat ovat silloin tyytyväisiä ja saavat toteutettua suurimman toiveensa. Se, että pelkän peruskoulun käyneiden vanhempien lapsi ei pääse vanhempien toiveesta huolimatta yliopistoon, ei olisi yhtä suuri vahinko, koska vanhemmilla itselläänkään ei ole yliopistokoulutusta. Heillähän ei ole yliopistokoulutusta, jonka "jättää perinnöksi”. Koulutuksen ja varallisuuden periytymisen ihailu tarkoittaa nollasummapelin oloissa sitä, että myös vähävaraisuuden ja vähäisen koulutuksen periytyminen nähdään hyvän yhteiskunnan tunnusmerkkinä.

En oikein pysty näkemään tällaisen järjestelmän oikeutusta. Ehkä kirjoittaja ei ole ajatellut asiaa loppuun saakka.

\section{MAKSULLISEN KULTTUURIN PUOLESTA}

Pursiainen kritisoi suorastaan raivokkaasti kulttuurin, taiteen ja urheilun tukemista julkisilla varoilla. Tukia pitäisi vähentää reippaasti ja antaa kulttuuritarjonnan kehittyä yksityisenä bisneksenä. Julkinen rahoitus tuhoaa taiteen ja taiteilijan riippumattomuuden. Kritiikissään hän ei epäröi käyttää populistisiakaan sanakäänteitä.

Erityisesti oopperan tuki on Pursiaiselle kauhistus. Jos oopperan kaltaisia elitistisiä taidemuotoja ei pystytä tuottamaan normaalina yksityisenä yritystoimintana, ei maassa tarvita oopperaa lainkaan, on hänen kantansa. Pursiainen ei ehdota kulttuuritukien lakkauttamista kokonaan, mutta jättäisi selvästi nykyistä suuremman osan käyttäjien ja mesenaattien maksettavaksi ja valitsisi tuettavat kohteet uusin perustein. Näitä uusia kriteereitä hän ei esittele.

Näkemyksen taustalla on ilmeisen vahva usko siihen, että isoja kulttuurija taidehankkeita syntyy yksityisellä rahalla ja niitä voidaan pitää yllä yritystoimintana. Useimmat toki toivoisivat tätä, mutta kaikilla ei ole Pursiaisen vahvaa uskoa sen toteutumiseen. Jotka eivät usko, ovat synkkää väkeä. Toisaalta, kun Helsinkiin yritettiin saada rakennettua 130 miljoonaa euroa maksavaa Guggenheim-museota, yksityisiä rahoittajia ja mesenaatteja ei löytynytkään. Se lienee osoitus siitä, 
että aie oli typerä ja järjetön. Mutta tapaus osoittaa myös sen, että yksityisen rahan saaminen kulttuurille ei ole niin todennäköistä kuin mielellämme toivoisimme.

Julkisten kulttuuritukien tuhoava vaikutus konkretisoituu Pursiaisen mukaan esimerkiksi Töölönlahden ympäristössä, jossa "yksi kaupungin hienoimmista alueista on muutettu kuolleeksi eliittikulttuurin mausoleumipuistoksi". Rappio jatkuu, kun alueelle rakennetaan "keskustakirjasto, josta tulee 100 miljoonan euron hautapaasi kuolevalle paperikirjalle." (s. 216)

Kirjastolaitos sellaisena kuin se on Suomessa kehittynyt, on Pursiaisen mukaan muutenkin aikansa elänyt. Rohkenen epäillä kirjoittajan asiantuntemusta kirjastosta kuolevan paperikirjan hautapaasina. Ei kirjastolaitos sentään niin pihalla ole teknologian kehityksestä, vaikka haluaisikin tarjota maksuttomia palveluja.

Pursiaisen mielestä kunnan- ja kaupunginkirjastot tulevat vääristäneeksi kansalaisten ymmärrystä ja sivistystä suosimalla suomenkielisiä kirjoja englanninkielisten kirjojen kustannuksella. Suomalaiset eivät kirjastoissa pääse lukemaan maailman parasta kirjallisuutta, vaan joutuvat tyytymään suomenkieliseen tarjontaan. Hän pahoitteleekin sitä, että niin monet edelleen pitävät suomalaista kirjastolaitosta hienona saavutuksena. Kirjastot ovat mitä ilmeisimmin juuri sellainen verovaroilla ylläpidetty julkinen laitos, josta olisi jo aika luopua. Pursiainen ei tosin ehdota, mikä sen korvaisi, vai korvaisiko mikään. Ehkä olisi aika perustaa niiden tilalle yksityisiä lainaamoja, joita kuukausimaksullisina jo onkin.

\section{KOLME KRIITTISTÄ POINTTIA}

Paska Suomen kolme pahinta kompastuskivet ovat sen kommunikoivuudessa. Kirjoja kirjoitetaan luettavaksi, mutta Pursiainen panee (ilmeisesti) tahtomattaan (tai puuttuvan kustannustoimittajan takia) lukijan jaksamisen koetukselle. Tekstissä on toistoa aina jankuttavuuteen asti. Kun Pursiainen tarttuu johonkin teemaan, hän tykkää toistaa taivasteluaan sivukaupalla ja melkein samoilla sanoilla.

Kirjoittaja näyttää huomanneen sen kyllä itsekin. Hän joutuu kymmeniä kertoja (en ole laskenut) toistamaan "kuten on jo useita kertoja todettu", "kuten jo totesin", "kuten sanottua". Monin paikoin pystyy hyvin seuraamaan kirjoittajan ajatusta, vaikka lukisi vain joka kolmannen sivun. Kustannustoimittaja olisi tehnyt lukijalle palveluksen tiivistämällä kirjan satasivuiseksi pamfletiksi. Asia ei olisi kärsinyt. Päinvastoin: viestin läpimeno olisi helpottunut.

Paska Suomi on ylikuormitettu äärimmäisyyksillä ja ylisanoilla (kukaan ei koskaan mitään missään, kaikki aina kaikkialla), mikä syö sanotun uskottavuutta. Kyllähän pamfleteissa usein kärjistetään, mutta en muista ennen lukeneeni näin äärimmäistä tekstiä. Hakematta tulee mieleen Yhdysvaltain nykyisen presidentin tapa hakea sanomisilleen huomiota esittämällä asiat absurdiuteen saakka liioiteltuna: "the greatest mess anyone has ever seen", "the biggest witch hunt in history". Kirjan tyyli toki tällä tavalla kiinni ajassa, mutta se ei ole kovin myönteinen asia.

Kolmas asia, jossa lukija kaipaa kohtuullisuutta, on henkilöön käyvä solvaaminen. Presidentti Donald Trump on tässäkin lajissa eräänlainen virallinen malli: "low IQ crazy Mika Brzezinski", "psycho Joe Scarborough" ja niin edelleen. Esimerkiksi Helsingin yliopiston kansainvälisen politiikan professoria Pursiainen nimittelee Trumpilta tuttuun tyyliin "tiedevastaiseksi kaupittelijaksi" ja "paikalliseksi hörhöilijäksi".

Viime vuosina on puhuttu paljon siitä, että solvaamisen ei toivoisi yleistyvän sen enempää sosiaalisessa kuin perinteisessäkään mediassa. Mutta kun huomiota on saatava ja kirjaa markkinoitava, epähienotkin keinot nähdään sanomisen vapauden nimissä luvallisiksi. Tai ehkä siitä on tullut somemaailmassa viihtyville toinen luonto.

\section{KESKUSTELUN AVAUS?}

Pursiainen pahoittelee kirjassa "yleisen typeryyden" ja "anti-intellektualismin" leviämistä Suomessa, mutta ei hänenkään ilmaisuaan voi intellektuaaliseksi kuvata. Siitä puuttuu keskustelevuus. Se on enimmäkseen paisuttelevaa oikeassa olemista muiden typeryyttä taivastelemalla.

Asiat, joista Pursiainen kirjoittaa, ovat yhteiskunnallisesti tärkeitä ja ansaitsisivat monipuolisempaa erittelyä. Nyt kirjoittaja hukkaa tilaisuuden tarpeettomasti roiskimalla ja meuhkaamalla. Aivan kuin me emme vähemmällä kuulisi.

Käytetyllä sivumäärällä olisi päässyt huomattavasti analyyttisempaan diagnoosiin Suomen tilasta.

\section{HEIKKI SILVENNOINEN}

professori, päätoimittaja

Turun yliopisto 